general practice was 'just a question of experience'. Realizing that others would be likely to face similar problems, he wrote a brief introductory textbook which he called 'The Art of General Practice'. It was well received by many new entrants to general practice as well as undergraduates. During the intervening decade, general practice has become a part of the curriculum of most Medical Schools in Britain as well as overseas. Specific postgraduate training (vocational training) has been accepted as a prerequisite to every branch of the profession.

Studies in and into primary medical care have identificd more precisely the role and function of the family doctor: many of these studies, incidently, were carried out by David Morrell, now Head of the Department of General Practice at St Thomas's Hospital, which is part of the University of London. In other countries that which is called general practice in Britain is often given a different title: for example, the name 'family medicine' is preferred in North America. Primary Medical Care is a name now preferred by many as it encompasses both general and family practice.

As a result the second edition of his book has become more of a textbook than its predecessor adding authority to the wisdom previously offered. This book which should be read by all who are thinking of going into primary medical care, whether as general practitioners, family doctors, emergency room physicians, primary care paediatricians or internists. Students having part of their training in such a situation would also benefit from reading it. It is well written. The message is clear. It is not, of course, a substitute for a clinical textbook on primary care. It is exactly what it is called: An introduction.

\section{Medical Care in Schools}

By M. Willis and M. E. Mclachlan. Pp. vii +216 , illustrated, soft cover, Edward Arnold: London, 1977. $£ 3.25$.

School teachers are frequently confronted by a child who is unwell, either with an acute illness or from an accident, and many have in their class a child with a chronic disability. What do they do? Presumably most learn by experience or by asking other teachers or a school doctor for advice about a specific problem. Here is a book to which they can refer in all such cases and which has been written specifically with their needs in mind.

The coverage is quite extensive including, for example, one section on the medical problems of immigrants and another on the medical requirements and the problems associated with school journeys.

The first five chapters together provide a description of the school medical service and how the teacher can relate to it. The medical section proper starts with a chapter on first aid followed by another on emergencies. Succeeding chapters describe the ordinary medical problems of childhood; how these can affect the child at school; what the teacher needs to know, and what the teacher should do if anything goes wrong. Also included are chapters on infectious diseases, psychological and mental disorders (quite rightly separated), as well as skin disorders and developmental problems. Not forgotten are the difficulties encountered with children who smoke, drink or take drugs.

This is a book which school doctors can recommend to their teacher colleagues, even though in places they may disagree with what has been written. (For example, only a proportion, perhaps less than half the cases of athlete's foot, are due to a fungal infection: most are intertrigo.) There are also some errors which can be corrected in the next edition: for example 'Mandies' (Mandrax) are not barbiturates.
Operative Surgery: The Hand

(3rd edition)

General editors: Charles RoB and Rodney SMITH; consultant editor: Hu R. GuY Pulvertaft. Pp. 407, illustrated, hard cover, Butterworths: Sevenoaks, 1977. $£ 25.00$.

Hand surgery, once a somewhat neglected topic, relegated to the junior Casualty Officer, has now achieved its rightful place as an important sub-speciality. And many young working people with injured or crippled hands have much to be thankful for in this respect.

This magnificent volume is part of the new third edition of one of the most popular series in operative surgery to be published in the English language. It has been brought completely up to date and includes new sections on anaesthesia, instrumentation, microsurgery and digital replantation, silicone tendon implants, high pressure injection injuries, reconstruction of the multilated hand, cerebral palsy and entrapment neuropathies in the upper limb. These are in addition to the standard sections on congenital deformities, early and late trauma, burns, infections, Dupuytren's contracture, rheumatoid arthritis, and so on. The chapters on tendon injuries, as might be expected from the eminence of the editor in this field, are especially rewarding. The twentyfive contributors include specialists from the U.S.A., India, Australia and Sweden as well as from the U.K. The text is authoritative and the illustrations (mainly line drawings) are clear and easy to follow. This new edition will prove valuable to orthopaedic and plastic surgeons as well as to general surgeons who are called upon to deal with operations on the hand.

\section{Operative Surgery revision}

(3rd edition)

By John J. Shipman Pp. 192, hard cover. H. K. Lewis London, 1977. £5.00.

The Fellowship in surgery of the various Royal Colleges is difficult hurdle to cross and there is no doubt that many can didates find the operative surgery section of the examination particularly awe-inspiring. Of course there is no substitute for careful practical tuition in the operating theatre supplemented by the study of the major textbooks, monographs and atlases, but Mr Shipman's little revision book, now in its third edition, has proved a useful aide-mémoire to many students. The author covers the principal operations of general and orthopaedic surgery, together with urology thoracic surgery, neurosurgery and operations on the ear and eye. These are presented in note form and in this third edition topics such as highly selective vagotomy and right hepatic lobectomy have been added. The student is advised first to write down the steps of the operation and then to check his own notes against the text. This will certainly continue to prove an assistance to the postgraduate in his revision and should help to mitigate some of the horrors of the "operative oral'.

\section{Practice, a Handbook of Primary Medical Care}

Edited by Jack Cormack, Marshall Marinker and DAVID Morrell. Third instalment. Kluwer-Harrap, London; 1977. £6.50.

The publishers report a very favourable reception to the first two instalments of this handbook, both in Britain and overseas. In the third instalment 20 further chapters have been added, all of them in the section on disease presentation 'Complaints'.

\section{The Principles and Practice of Clinical Trials}

Edited by C. S. GooD. Pp. 201, hard cover. Churchill Livingstone: Edinburgh. 1976. $\mathbf{6} 6.50$.

This volume contains the papers presented at a 1976 symposium organized by the Association of Medical Advisers in 
the Pharmaceutical Industry (AMAPI). It replaces another of the same title published in 1970 (Ed. by E. L. Harris and J. D. Fitzgerald) also based on a symposium organized by the AMAPI. The latter was a very popular book which is now out of print.

Most of the contributors to the 1976 volume are new and it appears to lack the breadth and depth of information included in the former, and does not therefore replace it. Some of the same aspects of clinical trials are covered in more than one chapter, and authors differ in their views on the same subject. There are also occasional, though rare, errors of fact and a few chapters have not been sufficiently well adapted from the spoken word. Inclusion of the discussion from the symposium was a mistake. Despite this, there are many valuable contributions and much good advice for those concerned with clinical trials and clinical research.

Professor Vere raises many issues in his chapter on the ethics of clinical trials. He does not answer them all and makes some suggestions that are clearly controversial. Dr Cuthbert all too briefly outlines the regulations which apply to clinical trials in the U.K. via the Medicines Act. Chapters by Drs James and Smith quite adequately cover the phases for investigation of a new medicine, but one must take issue with Dr Smith over some of the studies he proposes for the period after a new medicine has reached the market (Phase IV). They should surely have been made earlier, and before Phase IV? Some other contributions lack depth and content, and Dr Harcus missed an ideal opportunity to examine more fully the problems of monitoring adverse reactions. Perhaps his chapter was written too early to catch the current concern and spate of publications on this subject. Dr Clifford Hawkins' chapter on the presentation of data is his usual masterpiece on this subject, and a valuable contribution. Some of the best and most useful chapters are amongst the last five, devoted to clinical trials with specific classes of medicines or to specific disease entities.

This volume contains sufficient of value to recommend that it should be read and retained by all those concerned with clinical trials or clinical research. But if you are fortunate enough to have a copy of the 1970 volume, you should keep it, it has not been rendered obsolete by this new book.

\section{Problems of Childhood}

(Series of Articles on the Problems of Childhood published in the B.M.J. in 1976.) Pp. 149, soft cover. British Medical Journal: London, 1976. £2.50 (Inland) $\$ 6.25$ (Abroad US) including postage.

Like most collections of children's short stories there is something in Problems of Childhood to suit the taste of a wide variety of reader. The gifted individual with a relish for facts at any cost to his digestion will no doubt pounce upon $\mathrm{Dr}$ Whaton's article on bottle-feeding. The passivist will savour Mr Sharrard's advice on knock knees, bowlegs, intoeing, etc., 'all sit and wait'-such refreshing rare counsel from an orthopaedic surgeon. But the activist's hunger is also catered for. Dr Downham sweeps away just about every contra-indication to (or controversy against) immunization.

The reactionary (in this case the anti-psyche) perhaps has most to his liking. He will derive immense appetite for $\mathrm{Dr}$ Clayden's classification and explanations for constipation and soiling (how much Hirschsprung disease is being missed by those more head-than tail-orientated?). Breast feeding (Dr Addy) no longer needs Freud to extol its virtues with so much organic science. Even Dr Dodge's slant on recurrent abdominal pain in childhood tends to recoil from the masterful experience of Apley who has shown clearly that the psychosomatic cause is not one of exclusion of organic cause but vice versa. Those looking for plain, nourishing substance will find some excellent pickings: Sarsfield on wheezing children, Meadow on urinary problems, Hatcher on diarrhoea and Harcourt on squint.

Primarily directed at G.P's, a series of articles appearing in the BMJ in 1976 collected together and revised, this book at $£ 2.50$ ( $\$ 6.25$ in USA) is very good value. It should attract a wide readership among medical students and paediatric house officers. Sadly it lacks any semblance of humour or journalistic style.

\section{Recent Advances in Clinical Virology. No. 1}

Edited by A. P. WATERson. Pp. viii +200 , illustrated, hard cover. Churchill Livingstone: Edinburgh, 1977. $£ 9.75$.

This book contains twelve reviews of relevance to the practice of clinical virology. As the editor emphasizes in the preface, clinical virology is not synonymous with medical virology because it includes veterinary as well as medical aspects. However, this volume is mainly devoted to human viral diseases.

There are reviews on the following subjects: herpes encephalitis; subacute sclerosing panencephalitis; Creutzfeldt-Jacob disease; the scrapie agent; rabies vaccination; human papovaviruses; cytomegalovirus vaccine; Lassa fever; Coxsackie virus infections and the heart; acute nonbacterial infectious gastroenteritis; rubella vaccines; measles vaccines.

In an area of medicine which is developing as rapidly as clinical virology, an up-to-date and comprehensive review, written by a specialist in a particular field, is most valuable in the struggle to keep up with recent developments and to evaluate them in terms of previous work. This collection of twelve such reviews is therefore a worthwhile purchase for all with an interest in virus disease of the human or animals. In addition, as one may gather from the list of titles, a substantial amount of the book is concerned with virus diseases of the central nervous system. This, together with the chapters on virus vaccines, should result in the book being welcomed by neurologists, paediatricians and workers in other clinical specialities.

Perhaps in the next volume of this series there will be a larger contribution from workers in the veterinary field, and if it reaches the high standard of volume 1 it is eagerly awaited by this reviewer.

\section{A Short Textbook of General Practice (3rd edition)}

By Denis Craddock. Pp. xvi +741 , hard cover, H. K. Lewis: London, 1976. $£ 12.00$.

It is nearly 25 years since the first edition of this book appeared. At that time general practice was in the doldrums and the idea that there might be a need for a textbook about it must have seemed strange to many. Although a College of General Practitioners had been formed in Britain, no examination was needed for entry. In this, the third edition, Denis Craddock - now the Honorary Librarian of the RCGP -has enlarged his text with the expressed aim of covering the syllabus for the Membership examination for that College. Although part of the text, particularly that relevant to administration within the NHS, is not directly pertinent to those who practise in other countries, the rest of the book certainly is. Indeed, many may well enjoy reading some facts about the British National Health Service.

The introductory five pages describe what general practice is all about, not only in Britain, and this section could well be read with advantage by those in hospital practice. There follow six short chapters on practice organization and then seven on normal development and behaviour from conception to the grave, with the last chapter in this section 